\title{
Sosialisasi Penggunaan Mesin Pemusnah Sampah Rumah Tangga untuk Menjaga Kesehatan dan Kebersihan Lingkungan
}

\author{
https://doi.org/10.25008/parahita.v1i1.39 \\ Dheasey Amboningtyas ${ }^{1}$, Leonardo Budi Hasiholan², \\ 1,2Universitas Pandanaran \\ Jl. Banjarsari Barat No.1, Pedalangan, Semarang 50268 - Indonesia \\ *Email Korespondensi: dheasey@unpand.ac.id
}

\begin{abstract}
Abstrak - Kurangnya kesadaran masyarakat terhadap lingkungan hidup dan kesehatan mejadikan sampah berserakan dan menumpuk di berbagai tempat. Adanya keterbatasan tempat pembuangan sampah menjadi hal yang sangat mempengaruhi masalah sampah tersebut. Salah satu efeknya dari kondisi itu adalah, banyak bermunculan penyakit akibat lingkungan yang kotor. Selain itu, penyumbatan air sungai juga terjadi karena masyarakat di sekitar sungai membuang sampah ke sungai, mengakibatkan ekosistem rusak dan komposisi air sungai tercemar. Untuk itu masyarakat perlu diedukasi untuk menjaga kebersihan dan mengelola sampah rumah tangga. Dalam konteks tersebu, dilakukan sosialiasi bagi masyarakat dengan menghadirkan sebuah mesin pemusnah sampah rumah tangga yang pembuatan dan pemakaiannya sangat mudah. Pembuatan mesin pemusnah sampah rumah tangga ini tidak memerlukan tenaga khusus atau teknisi, tidak menggunakan bahan bakar, dan hanya menggunakan listrik dalam ukuran watt standar. Dengan adanya mesin pemusnah sampah rumah tangga ini, maka masyarakat menjadi mudah untuk membakar atau memusnahkan sampah-sampah rumah tangga yang setiap hari menumpuk.
\end{abstract}

Kata Kunci: Kebersihan, sampah rumah tangga, peduli sampah, mesin sampah, hidup sehat;

\section{PENDAHULUAN}

Pengabdian kepada masyarakat merupakan wujud kristalisasi dan integralisasi dari ilmu yang tertuang secara teoritis untuk diterapkan secara nyata dalam kehidupan sehari-hari di masyarakat, sehingga ilmu yang diperoleh dapat diaplikasikan dan dikembangkan dalam kehidupan masyarakat.

Potensi yang dimiliki oleh warga Kelurahan Kedungmundu, Kecamatan Tembalang, Semarang, Jawa Tengah, khususnya di RW 05 dalam berbagai kehidupan cukup tinggi, namun pada sisi lain ditemui kenyataan masih ada ketidakpedulian warga dalam pengelolahan limbah sampah rumah tangga mereka.

Masyarakat di sana masih kurang memiliki kepekaan dalam menjaga kebersihan lingkungan. Padahal, kebersihan lingkungan sangat penting dalam menjaga kesehatan. Di sekitar Kelurahan Kedungmundu, terlihat pemandangan sampah berserakan sehingga mengganggu pemandangan dan menjadikan tempat itu kumuh.

Melihat kondisi itu, Tim Pengabdian kepada Masyarakat Universitas Pandanaran, Semarang berusaha mencari jalan keluar agar sampah-sampah tersebut dapat dihilangkan. Untuk itu dirancang sebuah upaya dalam bentuk edukasi terhadap warga agar mereka memiliki kepekaan dan kepedulian terhadap kebersihan lingkungan.

Dengan memahami kebersihan lingkungan, masyarakat diharapkan dapat menjaga kebersihan dan tidak lagi membuang sampah sembarangan. Dengan begitu, diharapkan masyarakat yang sehat dan lingkungan yang bersih dapat dihasilkan.

Sosialisasi mesin pemusnah sampah rumah tangga yang ramah lingkungan menjadi pilihan yang tepat dan berguna dalam meningkatkan minat warga sekitar Kelurahan Kedungmundu untuk tidak membuang sampah sembarangan. Untuk itu dirancang sebuah mesin penghancur sampah yang kemudian diberikan kepada masyarakat di sana, dan mengajarkan mereka dalam mengoperasikannya 
Mesin pemusnah sampah rumah tangga tersebut relatif murah harganya dan tidak memerlukan tenaga khusus atau teknisi untuk merawatnya. Mesin itu juga tidak menggunakan bahan bakar yang dapat menimbulkan polusi, karena digerakkan oleh tenaga listrik dengan watt kecil.

Dengan adanya mesin pemusnah sampah rumah tangga ini, masyarakat kemudian dimudahkan untuk memusnahkan sampah-sampah rumah tangga yang setiap hari menumpuk di lingkungan tersebut.

Kegiatan sosialisasi ini untuk memotivasi masyarakat dan menstimuli mereka untuk mengubah cara berfikir terhadap sampah. Kesadaran warga dalam menjaga lingkungan, serta menerapkan perilaku hidup sehat, tidak membuang sampah rumah tangga sembarangan, merupakan hasil yang diharapkan dapat tercapai melalui sosialiasi penggunaan mesin menghancur sampah rumah tangga ini.

\section{METODE PELAKSANAAN}

Pelaksanaan Pengabdian kepada Masyarakat ini dilakukan dengan metode sosialiasi bagi warga terkait arti penting menjaga kebersihan lingkungan demi menghasilkan kesehatan lingkungan. Untuk itu sosialisasi tentang konsep kesehatan dan kebersihan lingkunan diberikan kepada mereka. kemudian dihadirkan mesin menghancur sampah rumah tangga yang disediakan pihak universitas.

Tim memberi pelatihan bagaimana mengoperasikan mesin penghancur sampah tersebut (Gambar 1) agar optimal hasilnya. Mesin tersebut juga ramah lingkungan. Tim juga memberi tahu mekanisme kerja mesin dan cara perawatannya yang relatif mudah dikerjakan.

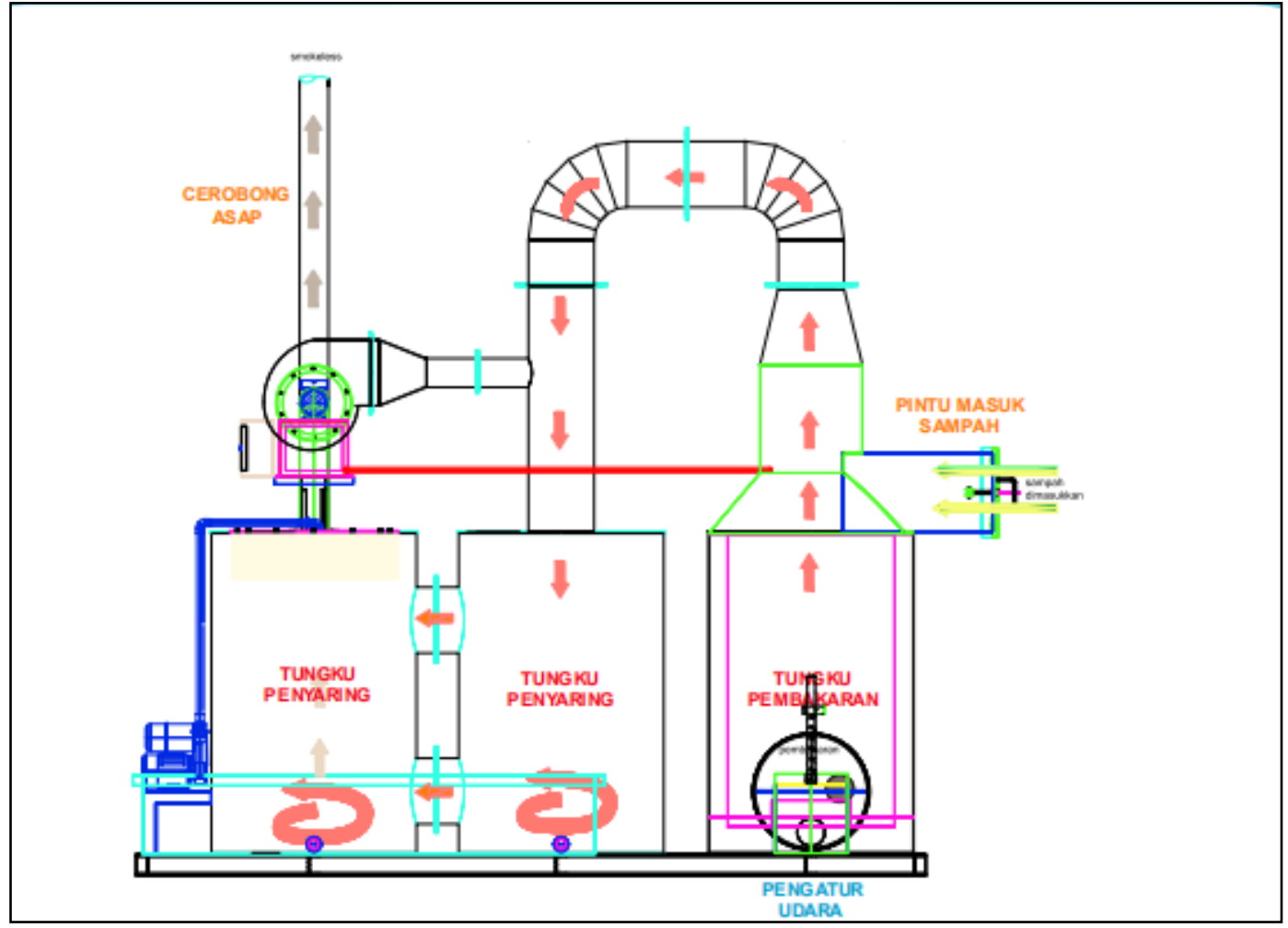

Gambar 1: Design mesin pemusnah sampah rumah tangga

Tahap yang dilakukan pada pengabdian masyarakat ini, meliputi: (1) Survey, dilakukan dengan pendekatan kepada ibu-ibu Pendidikan Kesejahteraan Keluarga (PKK) di Kelurahan Kedungmundu. Kegiatan itu dimaksudkan agar tepat sasaran dan memudahkan langkahlangkah kegiatan sehingga tercapai hasil yang maksimal; (2) Persiapan, dengan menentukan sasaran yang dijadikan objek kegiatan, dalam hal ini warga sekitar Kelurahan Kedungmundu. Langkah selanjutnya adalah mendata tamu undangan dan membuat undangan bagi mereka. Setelah itu menyiapkan tempat pelaksanaan serta peralatan yang dibutuhkan seperti LCD 
proyektor, kursi, presensi hehadiran, alat tulis serta konsumsi.

\section{HASIL DAN PEMBAHASAN}

Pelaksanaan kegiatan berlangsung dari pukul 20.00 WIB sampai selesai. Acara dibuka oleh moderator, diawali doa dan ucapan terimakasih. Setelah itu sambutan dari Leonardo Budi Hasiholan, S.E, M.M, sebagai wakil ketua tim, dan sambutan dari Dheasey Amboningtyas, S.E, M.M selaku ketua kelompok sosialisasi. Warga antusias mengikuti kegiatan tersebut.

Kelurahan Kedungmundu di Kecamatan Tembalang, Kota Semarang merupakan kelurahan yang strategis, berada di bagian bawah wilayah Kecamatan Tembalang, dikelilingi oleh jalan protokol (Jalan Kedungmundu Raya dan Jalan Fatmawati). Kelurahan Kedungmundu memiliki penduduk 10. 329 jiwa. Dengan banyaknya penduduk di kelurahan itu, maka pengelolaan sampah perlu mendapat perhatian.

Sampah adalah bahan sisa yang tidak dapat digunakan lagi, namun dapat diolah dan memberi nilai ekonomis. Jika sampah tidak diolah, maka sampah itu akan memberi dampak buruk bagi lingkungan hingga menyebabkan terganggunya kesehatan penduduk. Padahal, sampah yang didaur ulang bisa menjadi barang bernilai ekonomis. Sampah dapat dipisahkan dalam bentuk sampah organik dan sampah anorganik.

Sampah organik dan sampah anorganik memiliki banyak manfaat. Sampah organik dapat diubah menjadi biogas dan listrik, juga dapat diubah menjadi kompos atau pupuk organik serta bisa menjadi pakan hewan. Sampah anorganik, seperti botol plastik, atau bungkus plastik dapat diolah menjadi hiasan atau tas.

Dalam pengolahan sampah di Kelurahan Kedungmundu, Tim Universitas Pandanaran berupaya membantu warga Kedungmundu dengan memberikan mesin pemusnah sampah rumah tangga (Gambar 2 dan 3) yang ramah lingkungan agar mereka dapat mendapat manfaat dari pengelolaan sampah rumah tangga.

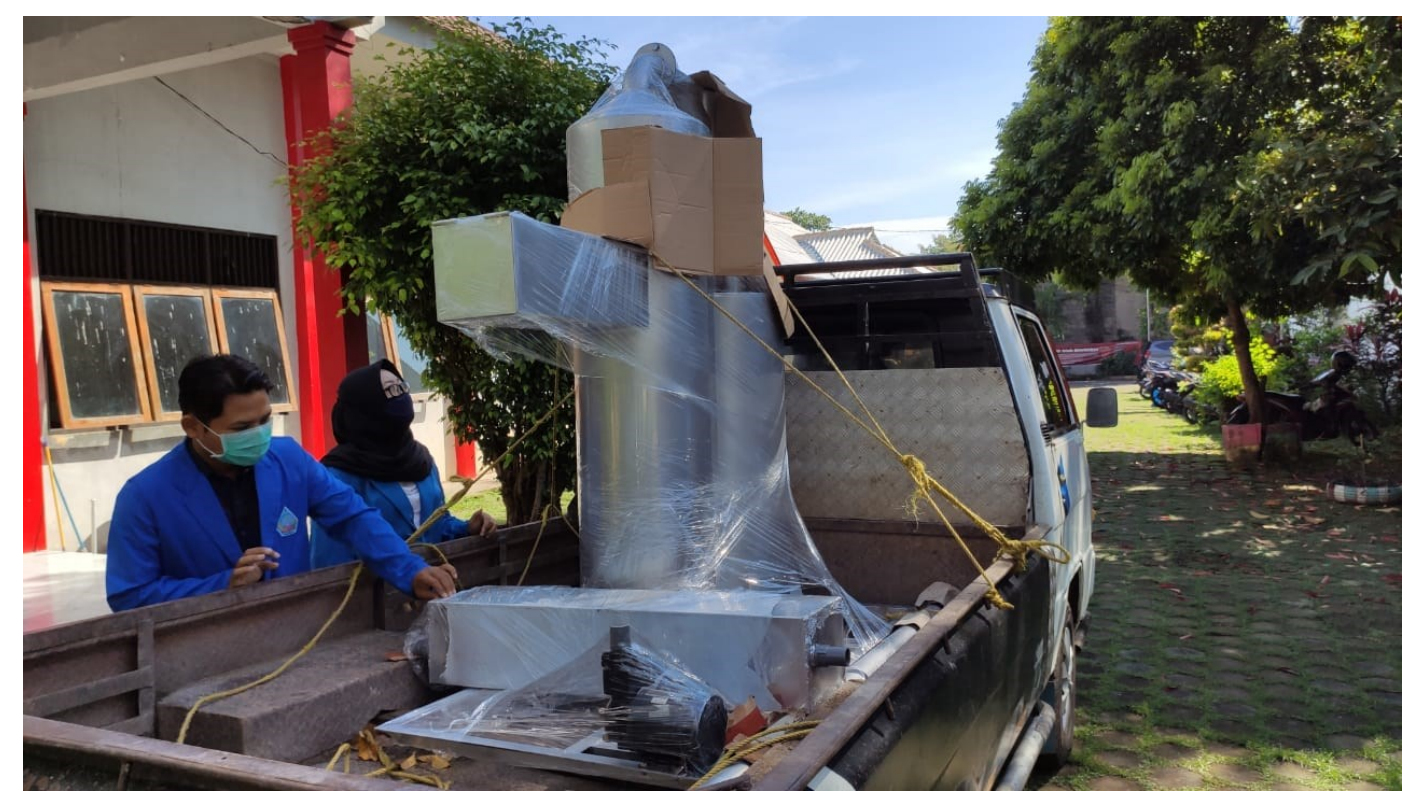

Gambar 2. Mesin Pemusnah Sampah 


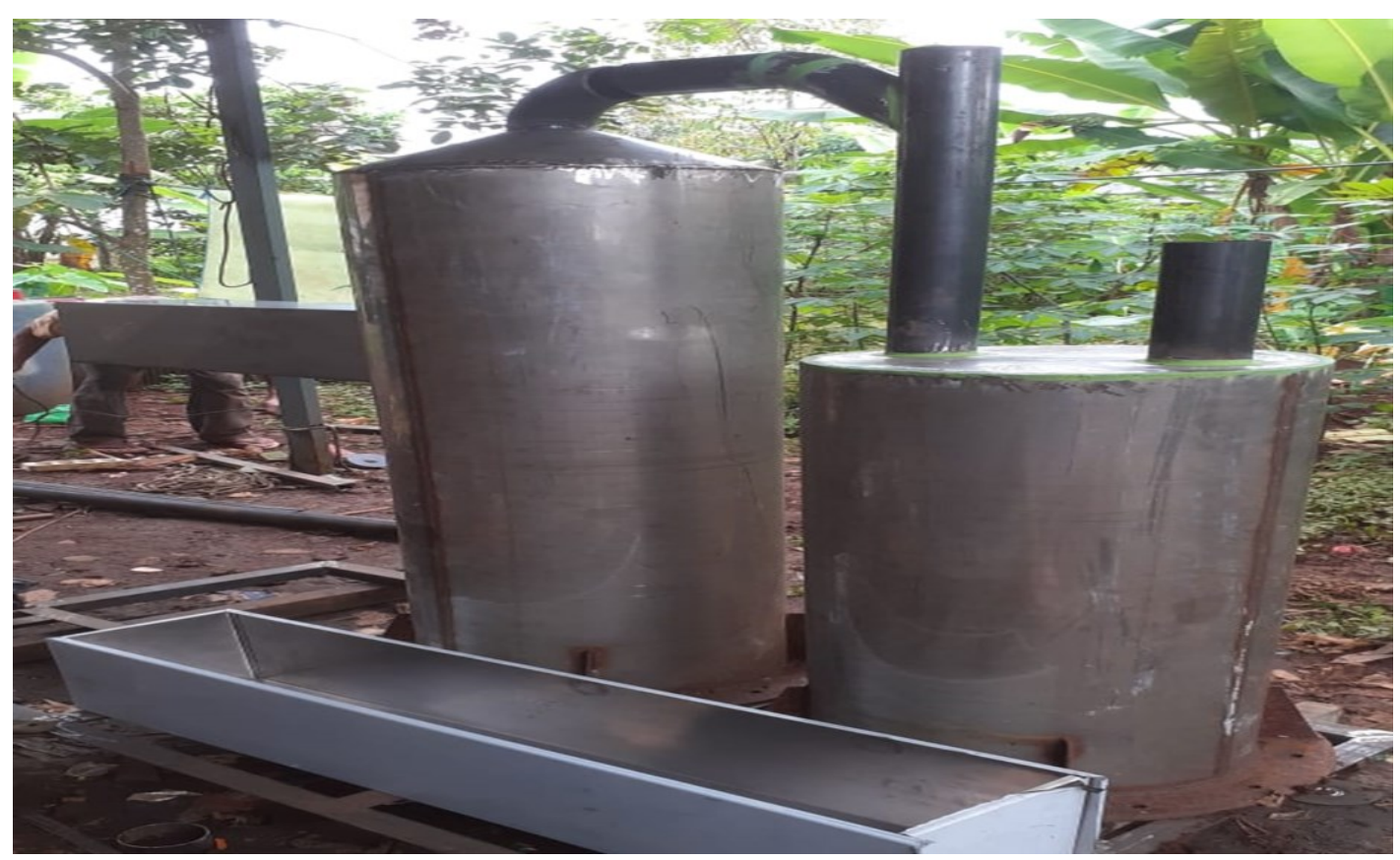

Gambar 3. Proses Pembuatan Mesin Pemusnah Sampah

IV. KESIMPULAN

Kesimpulan dari kegiatan sosialisasi yang diadakan tersebut adalah sebagai berikut: (1) sebelum sosialiasi berlangsung, masih ditemui kurangnya pemahaman warga terhadap arti penting menjaga kebersihan lingkungan; (2) acara sosialisasi berjalan lancar berkat dukungan dan partisipasi serta antusiasme warga dalam mengikuti kegiatan itu; (3) warga Kelurahan Kedungmundu mempunyai potensi yang besar pada sektor pengelolaan sampah dan dapat diandalkan untuk menjaga kebersihan; (4) hasil sosialisasi, warga kini memahami bahaya sampah yang tidak dikelola, karena dapat menyebabkan penyakit, banjir dan mencemari air bersih; (5) sosialisasi sangat berguna bagi warga karena mereka kini mendapat manfaat langsung dari hasil mengelola sampah rumah tangga.

\section{Ucapan Terima Kasih}

Tim Pengabdian kepada Masyarakat Universitas Pandanaran mengucapkan terimakasih kepada warga Kelurahan Kedungmundu, terutama RW 05, dan Lurah Kedungmundu serta pihak-erkait yang telah membantu sosialisasi ini hingga terlaksana dengan baik.

\section{Daftar Pustaka}

Hidayati, N. (2016). Mengelola Sampah, Mengelola Gaya Hidup. Retrieved from Walhi on line, 11 maret.

Ibnu, R, (2015). Pemanfaatan Sampah Organik sebagai Bahan Bakar dalam Bentuk Briket, MIPA Universitas Gadjah Mada, Yogyakarta.

Lestari, P., Ritonga, R., Ruliana, P., \& Barus, C.C. (2020). Disaster Communication Uses Field Training Exercise Simulation as an Important Aspect of Disaster Risk Reduction, Jurnal Komunikasi: Malaysian Journal of Communication, 36(1), 166-186.

Rochim, T. (2011). Proses pemesinan, Penerbit ITB.

Rusdiana, S (2008). Pengolahan sampah organik menggunakan reaktor komos dari bahan bambu apus, Jurnal Dimensi.

Ritonga, R \& Syahpurta, I. (2019). Citizen Journalism and Public Participation in the Era of NewMedia in Indonesia: From Street to Tweet, Media and Communication, 7(3), 79-90

Sabijanto A. (2006). Pentingnya Program Daur Ulang Sampah, Pikiran Rakyat, 18 Januari 
Syairozi, M., Rosyad, S., \& Pambudy, A. P. (2019). Pemberdayaan Masyarakat sebagai Pengguna Kosmetik Alami Beribu Khasiat Hasil Produk Tani Untuk Meminimalkan Pengeluaran Masyarakat Desa Wonorejo Kecamatan Glagah Kab. Lamongan. Empowering: Jurnal Pengabdian Masyarakat, 3, 88-98.

Yairozi, M. I. (2017). Prospek Pengembangan Ilmu Ekonomi Islam di Indonesia dalam Prespektif Filsafat Ilmu (Sebuah Kajian Epistemik). Jurnal Penelitian Ilmu Manajemen, 2(1).

Yulia, E., \& Sugiarto, E. (2018). Analisis Faktor yang Mempengaruhi Konsumen dalam Pembelian Keripik Singkong. Jurnal Ekbis: Analisis, Prediksi Dan Informasi, 19(2), 1100-1120. 